\title{
Health Information Management: Changing with Time
}

\author{
S. H. Fenton', S. Low ${ }^{2}$, K. J. Abrams ${ }^{3}$, K. Butler-Henderson ${ }^{2}$ \\ 1 University of Texas School of Biomedical Informatics, Houston, TX, USA \\ 2 Australian Institute of Health Service Management, University of Tasmania, Australia \\ ${ }^{3}$ Canadian College of Health Information Management, Canada
}

\begin{abstract}
Summary
Objective: With the evolution of patient medical records from paper to electronic media and the changes to the way data is sourced, used, and managed, there is an opportunity for health information management (HIM) to learn and facilitate the increasing expanse of available patient data. Methods: This paper discusses the emerging trends and lessons learnt in relation with the following four areas: 1) data and information governance, 2) terminology standards certification, 3) International Classification of Diseases, 11 th edition (ICD-11), and 4) data analytics and HIM.

Results: The governance of patient data and information increasingly requires the HIM profession to incorporate the roles of data scientists and data stewards into its portfolio to ensure dato analytics and digital transformation is appropriately managed. Not only are terminology standards required to facilitate the structure and primary use of this data, developments in Canada in relation with the standards, role descriptions, framework and curricula in the form of cerrification provide one prime example of ensuring the quality of the secondary use of patient data. The impending introduction of ICD-11 brings with it the need for the HIM profession to manage the transition between ICD versions and country modifications incorporating changes to standards and tools, and the availability and type of patient data available for secondary use.

Conclusions: In summary, the health information management profession now requires abilities in leadership, data, and informatics in addition to health information science and coding skills to facilitate the expanding secondary use of patient data.
\end{abstract}

\section{Keywords}

Health information management; information governance; International Classification of Disease Codes; terminology; health workforce

Yearb Med Inform 2017:72-7

hitp://dx.doi.org/10.15265//Y-2017-021

Published online August 18, 2017

\section{Introduction}

Health Information Management (HIM), the profession specifically devoted to health record science and classification/terminology, continues to play an integral role in ensuring the proper secondary use of patient data. In the past, the use of patient data was often limited by the nature of paper-based medical records that served as information sources for administrative or billing needs and research based on diagnostic and procedural indices created from the use of diagnostic and procedural/intervention coding systems.

The healthcare information technology and processing environment is changing at lightning speed and is only expected to accelerate. For example, the amount of healthcare data was estimated to be 153 exabytes in 2013, growing exponentially to an estimated 2,314 exabytes by 2020 [1]. However, key functionalities such as interoperability and predictive analytics will not be successful without effective data governance [1]. Adding to this is the growth of new sources of health data such as wearable fitness devices and home monitoring systems. This will result in very large amounts of healthcare data or big data, defined by Merriam-Webster as "an accumulation of data that is too large and complex for processing by traditional database management tools." [2]. A recent review by $\mathrm{Gu}$ and colleagues identified that big data research in healthcare has been focused on three areas over the last decade: 1) disease management and epidemiology; 2) technology for data mining and machine learning; and 3) health services such as personal health devices and electronic health records [3]. Shah and Pathak proposed that healthcare may finally be ready for big data, but they noted that the knowledge generated still has to be translated into practice [4].

The changes affecting the format and size of data sources, as well as the development of tools and methods, lead to foreseeable changes in the practice of HIM to manage and facilitate the secondary use of patient data. The purpose of this paper is to describe the results of a literature review and the findings from qualitative interviews with key opinion leaders in several key focus areas related to issues that are expected to have a significant impact on the practice of HIM, and hence the profession, over the next several years. In addition to searching the peer-reviewed literature, the authors sought unique insights from key opinion leaders in the chosen topics. The chosen topics are: 1) the increasing need for effective data and information governance; 2 ) the development of a terminology standards certification; 3 ) the release and implementation of the International Classification of Diseases, $11^{\text {th }}$ edition (ICD-11); and 4) the growing role of data analytics. The interviews related to information governance were conducted both in person and via email. The interviewees were asked their opinions related to the role between data and information governance; the similarities and differences between countries, and how to build capacity in workforce and resources. The face-to-face ICD-11 interviews focused on the ICD11 features different countries may use, standards development, parallel processing and other updated considerations, and any expected needs for mapping. While a myriad of topics could be included, these four were chosen because each is related to the ex- 
panded use of electronic health records and to the growth in the amount of digital data available for the maintenance of health and the treatment of diseases across the globe. For example, the practice of HIM in the U.S. will undergo significant changes with the implementation of value-based purchasing, but that initiative is not international.

\section{Data and Information Governance}

In conjunction with classification and terminology structures, data and information governance underpins the appropriate secondary use of patient data [5, 6]. In 2016, Gartner defined information governance as "the specification of decision rights and an accountability framework to ensure appropriate behavior in the valuation, creation, storage, use, archiving, and deletion of information. It includes the processes, roles and policies, standards and metrics that ensure the effective and efficient use of information in enabling an organization to achieve its goals" [7]. The key concepts of information governance include records and content management, information technology (IT) governance, data governance, data security and privacy, risk management and litigation readiness, regulatory compliance, long-term data preservation, and business intelligence [8]. Information governance should occur with all types of information (clinical and administrative), all media formats (paper, digital, images, and audio), and all types of health organizations [8]. Health data or information is often sensitive, personal data, and information that needs to be secure and protected from unauthorized access. Therefore, information governance is an essential requirement in any health care organization.

IT governance is one aspect of information governance, although these two terms are often incorrectly used interchangeably. Aspects of IT governance can be said to include efficient and effective decision-making related to IT, the application of leading practice when aligning IT endeavors with organizational strategies and objectives, and the incorporation of data governance principles. Data governance is the "processes and controls to ensure that information at the data level-raw alphanumeric characters that the organization is gathering and inputting - is true and accurate, and unique (not redundant)" [9]. The focus of data governance should be on the quality from the original source (root level) through subsequent uses (secondary use). It is the most basic, rudimentary, level of information governance and if not undertaken properly, the results will substantially affect all other levels of information governance. The difference between these three areas of governance - data, IT and information - are summarized in Figure 1.

Health data security and privacy are equally important factors in information governance. Cohn succinctly distinguishes health information privacy and security as "an individual's right to control the acquisition, uses, or disclosures of his or her identifiable health data ... Security ... refers to physical, technological, or administrative safeguards or tools used to protect identifiable health data from unwarranted access or disclosure." [10]. The increased digitization of information has resulted in many countries revising privacy legislation to address the issues resulting from the progression of the Internet of Things.

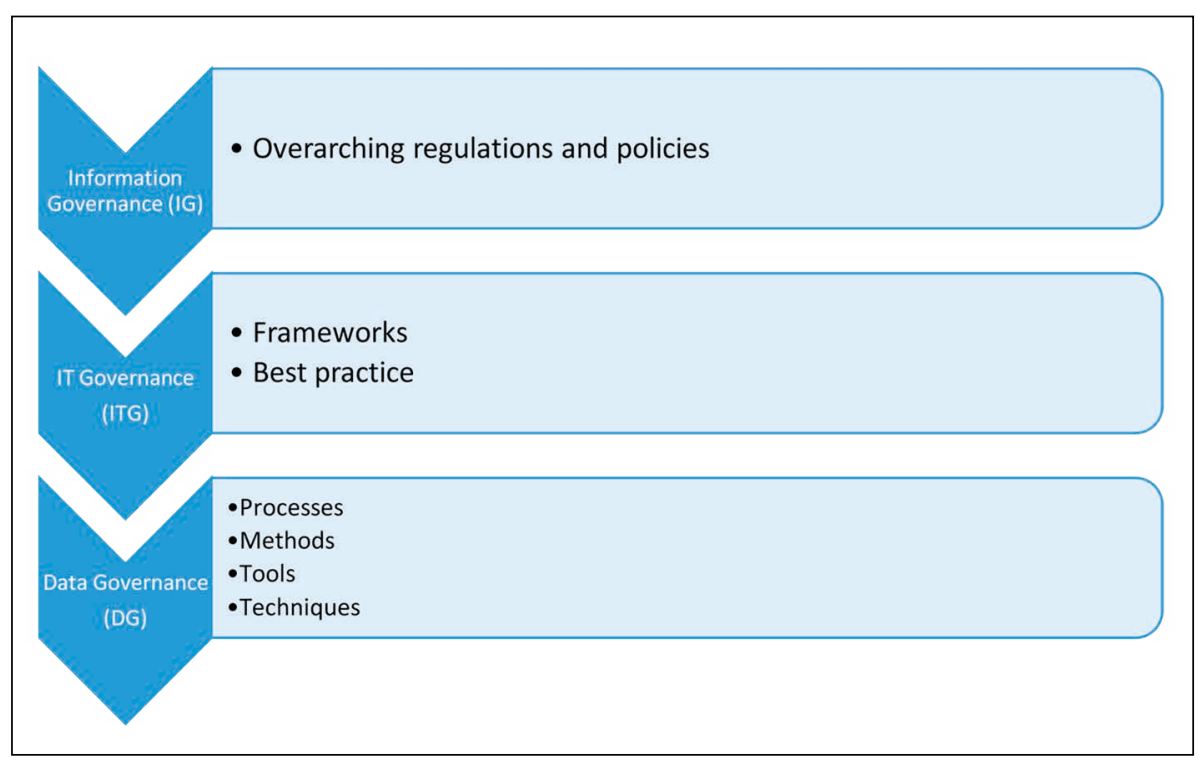

Fig. 1 Information governance, IT governance, and data governance
With the rapid transformation of digital data and information in health care, and because of the increasing use of mobile technology by a mobile population, there has been an increased emphasis on information governance in health care in recent years [1]. As an example, the U.S. Veterans Health Administration (VHA) has an Office of Informatics and Information Governance that leads their efforts to exchange data with non-VHA caregivers [11]. Health reforms, such as an increased focus on value-based payment and shared risk contracting, have resulted in a greater use of health and administrative data for service management purposes including planning, management, resourcing, and forecasting. Therefore, critical processes and tools for data governance support high quality data collection and maintenance. Adoption of an adequate information governance framework allows health care organizations to warrant that all health and administrative data is managed "legally, securely, efficiently, and effectively in order to deliver the best possible care to people who use health and social care services... [and for organizations] to ensure that information is used ethically." [12].

An examination of information governance from interviews with HIM key opinion leaders from five different countries demonstrates the varying levels of global 
adoption. Interviewees were selected as they were identified as experts in information governance in their country through presentations at a national or international level. Deborah Green, Executive Vice-President and Chief of Innovation for the American Health Information Management Association (AHIMA), stated that AHIMA sees the use of data and information as critical to the entire healthcare ecosystem and the health of individuals and populations. AHIMA developed the Information Governance Adoption Model ${ }^{\circledR}$, a tool that enables health care organizations to assess their information governance readiness, that defines ten organizational competencies of information governance for health care [13]. The ten organizational competencies are: strategic alignment, information governance structure, data governance, Enterprise Information Management (EIM), IT governance, analytics, privacy and security safeguards, regulatory and legal, awareness and adherence, and information governance performance. Each organization should assess itself against these organizational competencies to define its path to maturity in governing its information. Cameron Barnes, Director of Health Information Services and Information Governance for Cabrini Health and Education Committee, member of the Health Information Management Association of Australia (HIMAA), stated that one of the most challenging aspects of information governance is the sheer breadth of the work required and the general under-resourcing of the field. Considering the rapid digitization occurring in health, there is much work required in information governance without the supporting workforce, leading to risks about data integrity and useability. Barnes concluded that information governance in health should be viewed as a critical organisational-wide area and should be resourced to at least commence the building blocks that are required to establish appropriate frameworks and systems [14]. Paul Halliday, Business Intelligence Director Qatar, stated that in order to achieve successful information governance and the effective utilization of data, organizational collaboration is key. The data governance framework employed in Qatar includes infrastructure, roles and responsibilities, standards and monitoring, security, quality improvement, and monitoring [15]. The National Health Service in the United Kingdom also maintains an information governance toolkit developed by the Health and Social Care Information Centre (HSCIC). The toolkit allows organizations to assess themselves against the requirements for management structures and responsibilities, confidentiality and data protection, and information security. Where an organization's partial- or non-compliance is revealed, the organization must undertake appropriate measures in the aim of raising information governance standards and making cultural changes $[15,19]$.

These information governance initiatives across the globe are testimony to its current and future importance for the health information management profession. The effective and efficient secondary use of patient data cannot be separated from foundational information governance.

\section{Terminology Standards and Certification}

Terminology standards, e.g., Systematized Nomenclature of Medicine -- Clinical Terms [SNOMED CT], Logical Observation Identifiers Names and Codes [LOINC], provide a foundational structure in the digital healthcare environment to manage and facilitate the use of patient data; understanding and appropriately utilizing terminology standards is necessary to facilitate secondary data use [16]. Human resources sector studies, survey data, and a Canadian advisory group validated that a business need exists in the Canadian health care sector to address the current lack of workers trained and experienced in the use of clinical terminologies to support implementation and maintenance of digital health solutions [17]. Key stakeholders identified the development of a clinical terminology professional certification in Canada as a priority to help address this resource gap. The use of clinical terminologies across the country has grown due to increased investments in health information technologies $[16,18]$. In the context of this growing use of clinical terminologies, new and evolving roles to support e-Health are emerging.
In 2014, the business case for a Terminology Standards Certification was approved by senior representatives from Canada Health Infoway (Infoway) and the Canadian Health Information Management Association (CHIMA) Board of Directors. In addition, the Regenstrief Institute (in charge of the development of LOINC), the International Health Terminology Standards Development Organization (IHTSDO - responsible for SNOMED-CT), and the Canadian academic community confirmed their support for a clinical terminology professional certification in Canada. A multi-stakeholder committee led by CHIMA and Infoway completed the following initial steps:

1. Development of three terminology standards (TS) role descriptions - Terminology Specialist, Terminology Technical Specialist, and Terminology Advanced Specialist;

2. Development of a Canadian TS competency framework;

3. Creation of learning content items to support curriculum development.

The committee employed the Global Academic Curricula Competencies for Health Information Professionals [19] as the template for the creation of the Canadian Terminology Standards Certification Curricular Competencies [20]. The following five domains were developed to support the competency framework and the creation of learning content items:

1. Foundations of Controlled Terminologies; 2. Management of Controlled Terminologies; 3. Application of Controlled Terminologies; 4. Foundations of Interoperability Standards; 5. Application of Interoperability Standards.

Accreditation standards have been published and the development of a certification examination will be undertaken in 2017. In November 2016, a new work item proposal was presented to the International Standards Organization's Technical Committee 215 Health Informatics (ISO TC215) Working Group 3 (WG3), tabling to consider the development of an international standard for workforce roles and capabilities.

Adoption of a standardized process for educating and certifying TS workers will enable employers to confidently acquire 
personnel who are able to competently implement and maintain healthcare terminologies. A skilled TS workforce should support electronic health record and health information system implementations, thereby decreasing implementation delays and, ultimately, providing improved patient safety, in Canada and across the globe.

\section{International Classification of Diseases, $11^{\text {th }}$ Edition}

The International Classification of Diseases (ICD) has been used internationally for more than a century. The $11^{\text {th }}$ edition, ICD-11, represents a new method for combining classification and terminology to enhance the secondary use of patient data. The discussion within this paper focuses on the introduction of the new structures that use a foundational component and the subsets of the foundational component known as linearizations. The original goals for this new edition of ICD were i) to provide an ontological core developed in partnership with the International Health Terminology Standard Development Organization (IHTSDO); ii) to create a foundational layer with many entities that are not mutually exclusive, but have distinct definitions along with multiple relationships; and iii) to develop derivations of the foundational component known as linearizations, as mutually exclusive subsets fit for a particular purpose with a single parent within ICD-11 [21]. For example, a specific country may have a linearization specific to its payment or policy needs. As presented at the 2016 WHO-FIC Revisions Conference in Japan, the $11^{\text {th }}$ revision consists of the foundational layer or component and the linearizations. The primary linearization under development is that for Mortality and Morbidity Statistics and a Joint Task Force has been appointed to develop this linearization. The final version of ICD-11 is scheduled on the agenda of the World Health Assembly in May 2018 [22].

The implementation of ICD-11 can positively influence HIM practice through the following changes. Firstly, the existence of a foundational component with globally agreed upon definitions will help to ensure comparability and semantic agreement between the different national derivatives. Secondly, the potential existence of multiple linearizations allows for linkages and mappings between settings, countries, and possibly between ICD versions, and other terminological standards. Thirdly, the structure of ICD-11 uses post-coordination for duplicative attributes such as laterality, severity, and stage to reduce excessive repetition. Many countries considering the adoption of ICD-11 are seeking methods for creating software and tools to maximize the benefit of these changes. HIM practice and expertise will support the proper use and management of these systems.

HIM and clinical coding must prepare for a new era with an expanded use of standards and the system requirements (e.g., terminology mapping) to support ICD-11. Alignment of classification codes will evolve, most likely by using an automated code-from-text assignment process versus the current human methods [23]. One vision of the future includes clinically computable codes. Clinical computable coding involves pulling data from all parts of the electronic health record - laboratory data, medication data, device data, in fact, all machinable or computational data - rather than from those limited to dictated or recorded reports. Dr. Christopher Chute, Co-Chair of the World Health Organization ICD-11 Revision Steering Group, terms this "computable clinical criteria." [24].

Computable clinical criteria are related to the nature of the diagnosis of a disease, which is now recognized in healthcare as an imperfect science as many diseases have multiple and varied symptoms. A simple example is food poisoning which could have one or more of the following signs and symptoms: nausea, vomiting, watery diarrhea, abdominal pain/cramps, or fever. These are also most of the same signs and symptoms as dysentery. Diseases have different manifestations in different regions of the world and may present differently, hence, computable clinical criteria must be clear. Highly qualified coders or classification specialists will be able to assist in the development of the algorithms that use computable clinical criteria and to conduct audits to assess the quality of automated coding assignment.
Vera Dimitropoulos from the Australian National Centre for Classification in Health shared these thoughts regarding the pending implementation of ICD- 11 . "Transitioning between ICD editions and country modifications will require forward planning, perhaps parallel running, of the two classifications at the same time (e.g. maintaining the current classification whilst developing the new classification to ensure it is fit for purpose to suit clinical practice). Considerable lead time will be required from an IT infrastructure point of view to support the new classification structure (e.g. patient administration systems, morbidity coding tool vendors, mortality coding systems). Mapping is vital to ensure consistency with time series analysis and development of case-mix/activity based funding systems (groupers). Time and motion studies (dual coding studies - current vs. new) will be needed to determine the need of any increase in workforce (especially at the outset)." [25]. While the foundational coding classification and biomedical science education remain relevant for ICD-11, education and training in more technical skills such as computational thinking will be required. Consistency in the secondary use of patient data means that terminology and classification standards must continue to evolve.

\section{Data Analytics and Health Information Management}

Health record science and health information management are evolving to address the changing secondary use of patient data, introducing concepts from data science. The data scientist is an evolution of the data analyst/business analyst role and can be defined as one who is involved in the "acquisition and interpretation of data for business intelligence functions within the organization" [26]. The data scientist analyzes and interprets data into information and seeks new innovative sources of information from the available data. Data stewardship is primarily responsible for information and data governance in health care, while data analysis uses data and information for 
predictive modeling to inform clinical care and as a management tool for health care performance management [15].

Digital transformation will have a large impact on operational processes within performance management [27]. Data analytics is an important part of performance management as it allows managers to make decisions on real information rather than on historical performance or assumptions. With the forecasted explosion in data over the next three years [28], health service managers are looking for ways to invest in improved data collection and build a new workforce to support the collection of data and analysis for performance management [1].

Data is forecast to become the biggest growth area in health due to digital health transformation $[29,30]$. It will become the tool to drive policy change for an efficient and effective healthcare system [31] and interconnect providers and organizations to improve the monitoring of health outcomes and service quality. This explosion of available data brings a range of technical, governance, and compliance issues and as a consequence, there will be a greater need for health information management to incorporate data science methods to use and manage healthcare data over the next decade $[1,32]$.

\section{Conclusions}

The digital health transformation will require the HIM profession to evolve its core skill set and redefine its role in health, with Kloss acknowledging "HIM has a vital role to play to safely and effectively leverage health IT to benefit patients and improve system performance." [33].

The American Health Information Management Association (AHIMA) warns that "while the EHR hasn't changed the need or demand for HIM professionals' skills, it has dramatically changed the way those skills are applied and has accelerated the need for professionals to add new electronic-based abilities. ... [A] failure to adapt ... could lead to obsolescence, or at least provide an opportunity for non-HIM professionals to move into traditional and emerging HIM roles and take their place." [34].
The results of a 2015 AHIMA survey of Health Information Managers identified an anticipated decreased need for skills and competencies in coding and records management and an increased need for skills in the areas of leadership, data, and informatics over the next decade. In particular, respondents identified that the areas of data analytics/mining, informatics, and information governance will see the greatest growth in the field of HIM [35]. In 2015, Gibson, Abrams, and Crook identified in Canada the impact of emerging trends on Health Information Management, finding Health Information Managers are increasingly moving to roles such as data management and health information analysts, privacy and security officers, workflow analysts, project and program managers, and educators or trainers [36]. Most recently, the Department of Labor in the U.S. has recommended new Occupational Classification codes giving further support to the current and continuing evolution [37]. In a rapidly transforming healthcare system, the HIM profession needs to obtain and position itself as possessing essential, executive level set of functions and skills to remain relevant within health care organizations [33].

This survey paper has provided an overview on four key areas impacted by the evolution of electronically available patient data and the ongoing development of standards, structures, and terminologies. Each of these areas is linked to the secondary use of patient data and requires that health information management practices evolve to adapt to and facilitate the progress of emerging technologies. Challenges exist for HIM professionals to ensure they possess the relevant and applicable education, skills, and knowledge to match the requirements of the healthcare industry; and for the education system to produce highly educated HIM practitioners. The information and wisdom gleaned from the effective secondary use of patient data is needed as nations seek to improve their healthcare delivery systems and the health of their citizens.

\section{Acknowledgments}

The authors wish to acknowledge the expert input from Dr. Christopher G. Chute, Cochair of the ICD-11 Revision Steering Group and Bloomberg Distinguished Professor of
Health Informatics at Johns Hopkins Medicine; Cameron Barnes, Director Health Information Services and Information Governance for Cabrini Health and Education Committee member for the Health Information Management Association of Australia (HIMAA); Vera Dimitropoulos, Executive Manager, Classification Development, National Centre for Classification in Health; Deborah Green, Executive Vice-President and Chief Innovation of the American Health Information Management Association (AHIMA); and Paul Halliday, Business Intelligence Director, Qatar.

\section{References}

1. Corbin K. How CIOs Can Prepare for Healthcare "Data Tsunami" [Internet]. CIO. 2014 [cited 2017 Mar 21]. Available from: http://www.cio.com/ article/2860072/healthcare/how-cios-can-preparefor-healthcare-data-tsunami.html

2. Merriam-Webster. Definition of BIG DATA [Internet]. [cited 2017 Apr 16]. Available from: https:// www.merriam-webster.com/dictionary/big+data

3. Gu D, Li J, Li X, Liang C. Visualizing the Knowledge Structure and Evolution of Big Data Research in Healthcare Informatics. Int J Med Inform 2017 Feb;98:22-32.

4. Shah ND, Pathak J. Why Health Care May Finally Be Ready for Big Data [Internet]. Harvard Business Review. 2014 [cited 2017 Mar 22]. Available from: https://hbr.org/2014/12/why-health-caremay-finally-be-ready-for-big-data

5. Health Information and Quality Authority. Guidance on Information Governance for Health and Social Care Services in Ireland [Internet]. Dublin: Health Information and Quality Authority; 2012 p. 68. Available from: https://www.hiqa.ie/sites/ default/files/2017-01/Guidance-on-information-governance.pdf

6. AHIMA, AMIA. Healthcare Terminologies and Classifications: Essential Keys to Interoperability. Perspectives in Health Information Management. 2007;(Summer):7.

7. Gartner, Inc. Information Governance - Gartner IT Glossary [Internet]. [cited 2017 Mar 24]. Available from: http://www.gartner.com/it-glossary/information-governance

8. Smallwood RF. Information Governance: Concepts, Strategies, and Best Practices. 1 edition. Hoboken, New Jersey: Wiley; 2014. 442 p.

9. Smallwood RG. Defining the Differences Between Information Governance, IT governance, and data governance [Internet]. AIM Community. 2014 [cited 2017 Nov 29]. Available from: http://community.aiim.org/blogs/robert-smallwood/2014/08/18/defining-the-differences-between-information-governance-it-governance--data-governance.

10. Cohn SP. Privacy and Confidentiality in the Na- 
tionwide Health Information Network [Internet]. 2006. Available from: http://www.ncvhs.hhs. gov/060622lt.htm

11. Roling L, Jordan V.VA Virtual Lifetime Electronic Record [Internet]. The Sequoia Project; 2017 Feb; Washington, D.C. Available from: http:// sequoiaproject.org/wp-content/uploads/2017/02/ Feds-Combined-Deck.pdf

12. Health Information and Quality Authority. Health Information Governance [Internet]. [cited $2017 \mathrm{Mar}$ 24]. Available from: https://www.hiqa.ie/healthcare/ health-information/information-governance

13. Green DK. Information Governance; 2016.

14. Barnes C. Information Governance; 2016.

15. Halliday P. Information Governance; 2016.

16. Prism Economics adn Analysis. Health Informatics and Health Information Management: Human Resources Outlook, 2014-2019. Tornoto, ON, 2014. [Internet]. Toronto, ON; 2014 p. 102. Available from: https://www.echima.ca/uploaded/ pdf/reports/HI-HIM-HR-Outlook-Report-Final-wdesign.pdf

17. Abrams K, Bryan M. Business Case for a Clinical Terminology Professional Certification in Canada [Internet]. London, ON: Canadian Health Information Management Association; 2014 Mar p. 35. Available from: https://www.echima.ca/uploaded/ pdf/CCHIM/14Apr_Final\%20Approved_Business $\% 20$ Case.pdf

18. O'Grady J. Health Informatics and Health Information Management: Human Resources Report [Internet]. Toronto, ON; 2009. Available from: https://www.echima.ca/media/documents/ HIHIM_report_E_web.pdf

19. Global Health Workforce Council. Global Academic Curricula Competencies for Health Information Professionals [Internet]. Chicago, IL: AHIMA; 2015 [cited 2017 Mar 24]. Available from: http://www.ahima.org/about/global/global-curricula

20. Abrams K, Knight B. Canadian Terminology Standards Certification Curricular Competencies [Internet]. London, ON: Canadian Health Information Management Association; 2016 Mar p. 39. Available from: https://www.echima.ca/uploaded/
pdf/CCHIM/Canadian $\% 20$ Terminology $\% 20$ Standards\%20Certification $\% 20$ Curricular $\% 20$ Competencies.pdf

21. Fenton SH, Chute CG. Using Healthcare Data and Information. In: Fenton SH, Biedermann S, editors. Introduction to Healthcare Informatics [Internet]. Chicago, IL: AHIMA Press; 2013 [cited 2016 Nov 27]. p. 201-20. Available from: https://www.ahimastore.org/ProductDetailBooks. aspx?ProductID $=14700$

22. WHO Department of Health Statistics and Information Systems. Initial WHO Response to the Report of the External Review of the ICD-11 Revision [Internet]. World Health Organization; 2015 [cited 2016 Nov 27]. Available from: http:// www.who.int/classifications/icd/whoresponse. icdrevision.review.pdf?ua $=1$

23. World Health Organization. ICD-11 Beta Draft [Internet]. [cited 2016 Nov 28]. Available from: http://apps.who.int/classifications/icd11/browse/f/ en\#/http $\% 3 \mathrm{a} \% 2 \mathrm{f} \% 2$ fid.who.int $\% 2$ fictm $\% 2$ fentity $\% 2 f 718687701$

24. Christopher G. Chute. ICD-11 Development; 2016.

25. Dimitropoulos V. ICD-11; 2017.

26. Putnam S. Is a Data Steward a Data Scientist? [Internet]. The Data Roundtable. [cited 2017 Mar 24]. Available from: http://blogs.sas.com/content/ datamanagement/2013/10/29/is-a-data-steward-a-datascientist/

27. Westerman G, Bonnet D, McAfee A. The Nine Elements of Digital Transformation. MIT Sloan Management Review [Internet]. 2014 Jan 7 [cited 2017 Mar 24]; Available from: http://sloanreview. mit.edu/article/the-nine-elements-of-digital-transformation/

28. IBM Corp. IBM - Bringing Big Data to the Enterprise - What is Big Data? - Australia [Internet]. [cited 2017 Mar 24]. Available from: https://www. ibm.com/software/au/data/bigdata/

29. Boslet M. Finding Digital Health's New Business Model [Internet]. VCJ; 2016. Available from: https://jenniferjones.com/wp-content/ uploads/2016/06/Finding-digital-health.pdf

30. Imison C, Castle-Clarke S, Watson R, Edwards N. Delivering the Benefits of Digital Health Care
[Internet]. Nuffield Trust; 2017 Jan [cited 2017 Mar 24]. Available from: https://www.nuffieldtrust. org.uk/research/delivering-the-benefits-of-digital-health-care

31. Productivity Commission. Efficiency in Health - Productivity Commission Research Paper [Internet]. Canberra, Australia: Australian Government Productivity Commission; 2015 Apr [cited 2017 Mar 24]. Available from: http://www.pc.gov.au/ research/completed/efficiency-health

32. Fitzgerald PJ, Granada JF. Digital Health: The Revolution that Will Change Everything. Cath Lab Digest 2016 May;24(5).

33. Kloss L. Health Information Management in 2016 [Internet]. Wayne, PA: Precyse; 2012. p. 8. Available from: http://www.precyse.com/ resources/HIM\%20in\%202016\%20White $\% 20$ Paper_042412.pdf

34. Butler M. Adapt or Disappear: AHIMA's Reality 2016 has a New Mission to Transform the HIM Workforce through Education — or Else. J AHIMA 2014 May;85(5):24-9.

35. Sandefer R, Marc D, Mancilla D, Hamada D. Survey Predicts Future HIM Workforce Shifts. J AHIMA 2015 Jul;86(7):32-5.

36. Gibson CJ, Abrams KJ, Crook GF. Health Information Management Workforce Transformation: New Roles, New Skills and Experiences in Canada. Perspectives in Health Information Management (International 2015). p. 1-14.

37. Department of Labor. Standard Occupational Classification (SOC) System [Internet]. 2018 SOC Revision Process; 2016 [cited 2016 Nov 30]. Available from: http://www.bls.gov/soc/\#revision

\author{
Correspondence to: \\ Susan H. Fenton \\ University of Texas School of Biomedical Informatics \\ 7000 Fannin, Ste 600 \\ Houston, TX 77030 \\ USA \\ E-mail: susan.h.fenton@uth.tmc.edu \\ Tel: + 1 210-332-3525
}

